\title{
Arctic marine fungi: biomass, functional genes, and putative ecological roles
}

\author{
B. T Hassett $\mathbb{C}^{1} \cdot$ E. J. Borrego ${ }^{2} \cdot$ T. R. Vonnahme $\mathbb{C}^{1} \cdot$ T. Rämä $\mathbb{i}^{1} \cdot$ M. V. Kolomiets ${ }^{2} \cdot$ R. Gradinger ${ }^{1}$
}

Received: 22 September 2018 / Revised: 6 January 2019 / Accepted: 22 January 2019 / Published online: 11 February 2019

(c) International Society for Microbial Ecology 2019

\begin{abstract}
Recent molecular evidence suggests a global distribution of marine fungi; however, the ecological relevance and corresponding biological contributions of fungi to marine ecosystems remains largely unknown. We assessed fungal biomass from the open Arctic Ocean by applying novel biomass conversion factors from cultured isolates to environmental sterol and CARD-FISH data. We found an average of $16.54 \mathrm{nmol} \mathrm{m}^{-3}$ of ergosterol in sea ice and seawater, which corresponds to $1.74 \mathrm{mg} \mathrm{C} \mathrm{m}^{-3}$ (444.56 $\mathrm{mg} \mathrm{C} \mathrm{m}^{-2}$ in seawater). Using Chytridiomycota-specific probes, we observed free-living and particulate-attached cells that averaged $34.07 \mu \mathrm{g} \mathrm{m}^{-3}$ in sea ice and seawater $\left(11.66 \mathrm{mg} \mathrm{C} \mathrm{m}^{-2}\right.$ in seawater). Summed CARD-FISH and ergosterol values approximate $1.77 \mathrm{mg} \mathrm{C} \mathrm{m}^{-3}$ in sea ice and seawater $\left(456.23 \mathrm{mg} \mathrm{C} \mathrm{m}^{-2}\right.$ in seawater), which is similar to biomass estimates of other marine taxa generally considered integral to marine food webs and ecosystem processes. Using the GeoChip microarray, we detected evidence for fungal viruses within the Partitiviridae in sediment, as well as fungal genes involved in the degradation of biomass and the assimilation of nitrate. To bridge our observations of fungi on particulate and the detection of degradative genes, we germinated fungal conidia in zooplankton fecal pellets and germinated fungal conidia after 8 months incubation in sterile seawater. Ultimately, these data suggest that fungi could be as important in oceanic ecosystems as they are in freshwater environments.
\end{abstract}

\section{Introduction}

Fungi are ubiquitous members of global ecosystems that are responsible for biogeochemical cycling, forming symbiotic relationships, and producing secondary metabolites [1]. Fungi are among the most diverse [2] and under-studied organismal groups $(<10 \%$ of the estimated species are described) on earth [3] and exhibit a wide range of physiological plasticity enabling many taxa to survive in both freshwater and marine habitats. Approximately $60 \%$ of recorded marine fungi are described as obligate marine

Supplementary information The online version of this article (https:// doi.org/10.1038/s41396-019-0368-1) contains supplementary material, which is available to authorized users.

B. T Hassett

brandon.hassett@uit.no

1 UiT Norges arktiske universitet, BFE, NFH bygget, Framstredet 6, 9019 Troms $\varnothing$, Norway

2 Texas A\&M University, 435 Nagle Street, 2132 TAMU, College Station, TX 77833, USA species [4]; however, the frequency of habitat exchange and the ecological relevance of euryhaline taxa in opposing environments remains unknown. Regardless, the inconspicuous morphology of fungal propagules has challenged the easy identification and subsequent integration of fungal data into marine ecology. Consequently, marine fungi receive considerably less research attention, relative to other organismal groups. In ice-covered environments, there is mounting evidence that fungi are not only active community members, but are among the most predominantly detected eukaryotic taxa [5-7] that are seasonally dynamic [8] and abundant [9], especially in the Arctic [10].

Though little is known about the ecological contributions of marine fungi, studies of terrestrial and freshwater systems suggest that there are many potential avenues through which Arctic marine fungi could facilitate carbon flow. The Arctic marine environment is characterized by a patchwork of distinct, seasonally ice-covered seas [11] that receives $10 \%$ of the global river flux [12]. As the Arctic continues to warm, thawing permafrost comprised of refractory lignins and other aromatic carbon molecules are exported into the Arctic Ocean [13]. The biological fate of these substances, namely in regard to the eukaryotic microbial community at 
the base of the food web, remains largely speculative. However, fungi have historically been known to occupy this ecological niche in terrestrial environments by encoding lignin-degrading gene products [14]. In aquatic ecosystems, animal excrement in the form of fecal pellets can rapidly transport organic matter from the pelagic realm to benthic organisms [15]. Degradation of fecal pellets by bacteria and dinoflagellates [16] is known to alter the vertical flux of this organic material. Fungi dominate biomass on bathypelagic marine snow [9] and are known to degrade and recycle animal excrement [17] in the terrestrial realm. However, the relevance of marine fungi to the degradation of fecal pellets and the effects of this metabolism on higher trophic levels remains poorly characterized. Screening of rRNA molecular barcodes and clone data has detected fungal communities comprised of an uncharacterized phylogenetic branch of Chytridiomycota [18] that appear to be important prey for Arctic zooplankton [19]. These Arctic Chytridiomycota communities are primarily found with members of the Dikarya in sea ice, sediment $[8,20]$, and in association with driftwood [21]. Analysis of rRNA barcode data can inform richness estimates for assessing community complexity; however, these data cannot detail enzymatic potential, definitively ascribe an ecological role, or be converted into carbon (C) units.

In polar environments, maintaining the fluidity and integrity of the plasma membrane is essential to survival. In the plasma membrane, sterols provide structural support and serve as precursors for hormones. Primary eukaryotic sterols generally associate with the major clades of eukaryotic life: cholesterol in vertebrates, phytosterols in plants, and ergosterol in fungi [22]. Ergosterol $\left(\mathrm{C}_{28} \Delta^{5,7,22}\right)$ is the predominant membrane sterol in most of the Dikarya fungi (Ascomycota and Basidiomycota) [23] and has been used to estimate fungal biomass in a variety of ecosystems [24-26]. The use of ergosterol as a fungal biomarker is not suitable for the Chytridiomycota, as they do not synthesize ergosterol [27]. Understanding the ecology and biomass contributions of the fungi is important for integrating fungal contributions into food web analyses and informing ecosystem modeling efforts [28].

In this study, our objective was to take a holistic approach to examining the contributions of fungi to Arctic marine food webs. We first estimate fungal biomass in the open ocean and sea ice by generating and applying novel biomass conversion factors to integrated environmental sterol concentrations and Chytridiomycota-specific enzyme-labeled oligonucleotide counts. To supplement these biomass estimates, we explored the presence of known catalytic fungal genes in coastal surface sediment that can serve as a proxy for ecosystem functionality using the GeoChip microarray. To build on the detection of these functional genes, many with known degradative potential, we explored the ability of a marine fungus to germinate in zooplankton fecal pellets. Lastly because approximately $40 \%$ of marine fungi are known to exist in both terrestrial and marine realms, we wanted to test if one of these fungi could survive an Arctic seasonal cycle, under in situ temperature conditions without any added nutrients.

\section{Methods}

\section{Environmental sampling}

Environmental samples were collected from seawater and sea ice across the Arctic (summer) and from Troms $\varnothing$ air (October) in 2017 (Fig. 1; STable 1). Most of the samples were collected during the expedition PS106 in June/July onboard the German icebreaker R/V Polarstern. Additional samples were harvested close to Barrow, Alaska (station MBS) in 2014 (STable 1). Seawater was collected using a CTD/Rosette sampler in 101 Niskin bottles from the surface, chlorophyll maximum, and bottom depths at every station. At least one liter of seawater was collected to sample the suspended community, which was subsequently vacuum-filtered onto $47 \mathrm{~mm}, 0.2 \mu \mathrm{m}$ nuclepore filters (Sartorius, Göttingen, Germany) for high-throughput sequencing and sterol quantification. Catalyzed Reporter Deposition-Fluorescence In Situ Hybridization (CARDFISH) samples were fixed at room temperature for $30 \mathrm{~min}$ in $8 \%$ formaldehyde and subsequently filtered onto $0.2 \mu \mathrm{m}$ nuclepore filters (Sartorius) with an underlying support filter (Sartorius). Three ice cores were extracted at each sea ice station using a $9 \mathrm{~cm}$ Kovacs ice corer. The bottom $10 \mathrm{~cm}$ of each core was sectioned using an ethanol-sterilized handsaw. Ice core sections were melted at room temperature into 11 of $0.2-\mu \mathrm{m}$-filtered seawater. After complete melting of the ice cores, samples were vacuum-filtered onto $0.2 \mu \mathrm{m}$ filters. After filtration, all filters were immediately stored in sterile polypropylene tubes at $-80^{\circ} \mathrm{C}$ and kept frozen in the dark until analysis. Sediment traps with $72 \mathrm{~mm}$ diameter and 1.81 volume (Model 28.xxx series; KC-Denmark, Silkeborg, Denmark) were deployed at 5 and $20 \mathrm{~m}$ for $8 \mathrm{~h}$ and $37 \mathrm{~min}$ at a single ice station (station 80). To better interpret our ergosterol values and place our findings in a broader ecological context, we sampled a floating algal aggregate (SFigure 1) and deployed (on the ground) a Burkard cyclone spore trap (Rickmansworth, UK) to sample air $\left(16.51 \mathrm{~min}^{-1}\right)$ in Troms $\varnothing$, Norway for $1 \mathrm{~h}$. Surface sediment samples were collected in Barrow, Alaska in triplicate in May and June of 2014 using a ponar grab that was deployed through a hole in the ice. Sediment was stored in sterile polypropylene tubes and frozen at $-80^{\circ} \mathrm{C}$ until DNA extraction. 


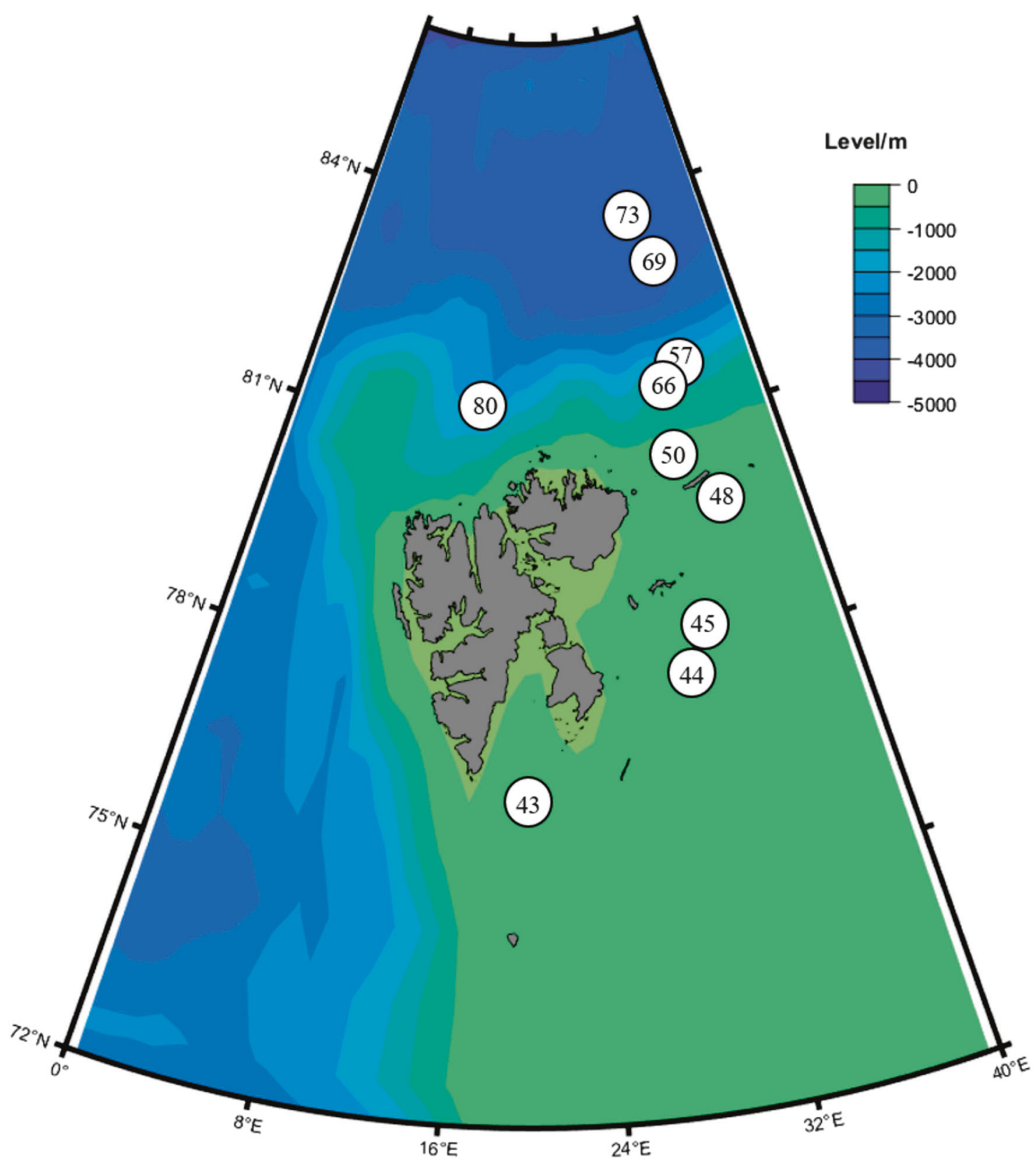

Fig. 1 Map of study site area and station locations around Svalbard (gray) sampled during the RV Polarstern expedition PS106

\section{DNA extraction and sequence processing}

DNA was extracted by bead beating filters in $10 \% \mathrm{wt} / \mathrm{vol}$ SDS lysis buffer for $10 \mathrm{~min}$ with a Precellys 24 shaker (Bertin, Frankfurt, Germany) at maximum speed, followed by a phenol-chloroform extraction. DNA was then purified using DNeasy PowerSoil Kit (Qiagen, Hilden, Germany) collection tubes and wash buffers, following the manufacturer's suggested protocol. For 18S rRNA gene sequencing analysis, target amplicons were generated by PCR (30 cycles) using the Earth Microbiome Project primers: Euk1391f: (5'-GTACACACCGCCCGTC-3') and
EukBr: (5'-TGATCCTTCTGCAGGTTCACCTAC-3') [29] to generate $\sim 170$ base pair reads specific to the V9 hypervariable region. PCR products were generated using fusion primers with the Fluidigm CS1 or CS2 universal oligomers added to $5^{\prime}$ ends. Sterile MilliQ water was used throughout filtering, DNA extraction, and primary PCR to screen for the presence of unintended contamination. Secondary PCR and sequencing was performed at Michigan State University's Genomics Core Lab. Secondary PCR was conducted with dual-indexed, Illumina-compatible primers to complete library construction. Final PCR products were batch-normalized using an Invitrogen SequalPrep DNA 
Normalization plate and products recovered from the plate were then pooled. The pool was quantified using a combination of Qubit dsDNA HS, Agilent Bioanalyzer DNA 1000, and Kapa Illumina Library Quantification qPCR assays. The pool was loaded onto two (i.e. sequenced twice to increase sequencing depth) standard MiSeq v2 flow cells and sequencing was performed in a $2 \times 150$ bp paired-end format using MiSeq v2 300 cycle reagent cartridges. CPCustom primers for sequence reads one and two, as well as index read one that was complementary to the Fluidigm CS1 and CS2 oligos, were added to appropriate wells of the reagent cartridge. Base calling was done by Illumina Real Time Analysis (RTA) v1.18.54 and output was demultiplexed and converted to FastQ format with Illumina Bcl2fastq v2.19.1. Duplicate data output generated from the two separate runs were then concatenated (Unix cat command) before sequence analysis. Sequence analysis and processing was conducted using Mothur v1.33.3 [30, 31]. Sequences with ambiguous base calls were eliminated $($ maxambig $=0)$ from all datasets. Sequences were aligned using the SILVA [32] reference database (Release 123), screened for chimeras with UCHIME [33], and classified with SILVA (Release 123), using the K-nearest neighbor algorithm (bootstrap cutoff value of $75 \%$ with 1000 iterations). Sequences classified as Bacteria, Archaea, and Metazoans were removed from datasets. Sequences were then clustered into operational taxonomic units at $97 \%$ similarity using the Average Neighbor distance.

\section{Isolates, carbon estimates}

Four marine Dikarya fungi and two cosmopolitan freshwater Chytridiomycota isolates (STable 2) were isolated and identified based on morphology, supplemented by $28 \mathrm{~S}$ rRNA and ITS1-5.8S-ITS2 DNA sequence data. Cells were harvested by inundating agar plates with sterile water. Harvested cells were sterilely sieved $(35 \mu \mathrm{m}$, Falcon \#352235; Corning, New York, USA), then counted, and sorted with flow cytometry (BD FacsAria III) into sterile glass vials containing phosphate-buffered saline (Biowest, Riverside, Missouri, USA). To estimate total carbon per cell, 100,000 sorted cells of each isolate were filtered onto precombusted glass fiber filters (Whatman, Maidstone, UK). Precombusted filters were then fumigated for $24 \mathrm{~h}$ in an enclosed container with hydrochloric acid (SigmaAldrich, St. Louis, Missouri, USA) and then allowed to dry for an additional $24 \mathrm{~h}$ at $56{ }^{\circ} \mathrm{C}$. Organic carbon was quantified from fumigated filters with a CEC $440 \mathrm{CHN}$ analyzer (Leeman Labs, Hundson, New Hampshire, USA). The carbon biomass per cell was estimated by dividing $\mu \mathrm{g} C$ measured with the CHN analyzer by the total number of cells sorted. These values were used to calculate the biomass per cell volume ratio, based on light-microscopically determined cell sizes assuming a shape of a sphere $\left(V=\frac{4}{3} \pi r^{3} ; \quad r=\right.$ range midpoint of light microscopymeasured cells) for Chytridiomycota isolates, and to create carbon:ergosterol values for the Dikarya isolates.

\section{Liquid chromatography mass spectrometer (LCMS) methods and biomass ratios}

Ten thousand cells of each Chytridiomycota and Dikarya species were harvested (as described above) and sorted in triplicate with flow cytometry (as described above), per species, to quantify sterol composition. Each sample was run in triplicate (technical replications) and standard errors were generated from the means of these values (STable 2). Prior to LCMS analysis, samples were treated with $1 \mathrm{ml}$ of 2:1 chloroform:methanol (v/v) and allowed to extract overnight at room temperature in the dark. Five microliters of extracts were injected into an Ascentis Express C-18 Column $(3 \mathrm{~cm} \times 2.1 \mathrm{~mm}, 2.7 \mu \mathrm{m}$; Sigma-Aldrich) connected to a Sciex API3200 LCMS/MS in (+) APCI mode, run with an acetonitrile isocratic mobile phase $(0.2 \mathrm{ml} / \mathrm{min})$, and analyzed with multiple reaction monitoring. Sterols were compared to chemical standards, ergosterol $(379.5>69.2$; Sigma \#45480), cholesterol (369.6 > 161.3; Sigma-Aldrich \#C8667), 24 $\alpha$-ethyl cholesterol (397.0 > 161.3; Cayman Chemical \#11756), 24 $\alpha$-methyl cholesterol (393.4 > 161.1; Caymen Chemical \#17344, Ann Arbor, Michigan, USA), and quantified against isotopically labeled cholesterol (371.9 > 161.1; Sigma-Aldrich \#707678). Conversion factors were then generated for isolates by dividing micrograms of carbon measured on filters by ergosterol values ( $\mu \mathrm{g} \mathrm{C}$ per nmol ergosterol). These values were used to determine and subsequently integrate (midpoint approximation) Dikarya biomass in the environment.

\section{CARD-FISH}

De novo probe design was conducted in ARB [34]. Arctic marine Chytridiomycota 28S rRNA clone sequences [18] were collated with all 28S rRNA Chytridiomycota sequences archived in SILVA [34] to design two Chytridiomycota-specific probes (probe BTH that was designed to target described taxa represented in SILVA and probe $\mathrm{BTH} 2$ to target clone sequences that represent undescribed lineages) using the specification min group hits $=40 \%$, nongroup hits $=30$. Using these parameters, we generated two probes: ChyBTH: 5'-GAATGAGAGCTTCTAGTGG-3' and ChyBTH2: 5' TAAAAGTGTTTTCGGGGGCA-3'. CARD-FISH was conducted using the SILVA FISH protocol v2.2 [35]. Specifically, filters were embedded in $0.2 \%$ low-melting agarose. After embedding and deactivation of endogenous peroxidases with $\mathrm{H}_{2} \mathrm{O}_{2}$, a double-hybridization was 
conducted to account for different melting temperatures of our probes. A chitinase permeabilization step was excluded, as there was a noticeable loss of Chytridiomycota cell structure during protocol optimization. Hybridization was conducted with horseradish peroxidase enzyme-tagged probes (Biomers, Ulm, Germany) and incubated with $35 \%$ (BTH) and $20 \%$ (BTH2) formamide concentrations at $46{ }^{\circ} \mathrm{C}$ for $1.5 \mathrm{~h}$ per probe. The optimal formamide concentration for each probe was determined by identifying the concentration that yielded the greatest specificity and signal in our target cells. Signal amplification was conducted using tryamide (Alexa594) at $46^{\circ} \mathrm{C}$ for $45 \mathrm{~min}$ per probe. After hybridization and signal amplification, filters were counterstained with DAPI and then mounted in Citifluor:Vectashield solution on glass slides and stored at $-20{ }^{\circ} \mathrm{C}$ in the dark. Filters were visualized under a compound epifluorescence microscope (Leica, Wetzlar, Germany) to enumerate labeled cells at 400× magnification. Laser scanning micrographs were generated on a Zeiss LSM880. Fluorescing cells larger than $1 \mu \mathrm{m}$ and smaller than $20 \mu \mathrm{m}$ were enumerated by counting 20 fields of view. Environmental concentrations were determined by extrapolating areas observed within our fields of view to the entire area of the exposed filter and standardizing to the volume of seawater filtered. These values were used to determine and subsequently integrate (midpoint approximation) Chytridiomycota biomass in the environment.

\section{Functional gene survey}

For functional gene analysis, DNA was extracted from triplicate under-ice surface sediment samples from Barrow, Alaska collected in May and June 2014. After extraction, DNA was pooled and analyzed using the GeoChip [36] functional gene microarray (GeoChip v5.0; Glomics Inc., Norman, OK, USA). Amplification, labeling, hybridization, imaging, and data processing were conducted by the Institute for Environmental Genomics at the University of Oklahoma according to published protocols [37]. Signal intensity was normalized to display all positive probes detected in each sample. Probe data were removed from the output if the signal to noise ratio was below 2 or if the signal was $<200$ or $<1.3$ times the background.

\section{Spore longevity}

Five hundred microliters of $1.1 \times 10^{6}$ Penicillium brevicompactum spores per $\mathrm{mL}$ were applied to $47 \mathrm{~mm}, 0.2 \mu \mathrm{m}$ pore filters (Sartorius). Spores were enumerated with a hemocytometer counting chamber (Hausser Scientific, Horsham, Pennsylvania, USA). Filters were folded in half and sealed with tape. Spore packets were then submersed into $0.2-\mu \mathrm{m}$-filtered seawater and incubated at $0{ }^{\circ} \mathrm{C}$. Filters were then removed monthly and placed on PmTG media overnight at room temperature. Incubated filters were then stained with Rose Bengal and microscopically examined for the presence of germinating spores.

\section{Spore germination in fecal pellets}

Onisimus glacialis (amphipod) was collected onboard the R/V Polarstern in July 2017. Ten days after collection, 60 fecal pellets were harvest from incubation jars and inoculated with Penicillium brevicompactum spores in sterile glass vials at $4 \mathrm{C}^{\circ}$ for 30 days. Pellets were stained with calcofluor white (Sigma) and visualized with fluorescence microscopy.

\section{Results}

LCMS analysis of cultured fungal isolates detected all targeted sterols, predominated by 24-ethyl cholesterol, followed by cholesterol, 24-methyl cholesterol, and finally ergosterol (STable 2). Midpoint ranges of zoosporangia (Chytridiomycota) and conidia (Dikarya) were used to establish biovolume estimates (Table 1). CHN output of carbon values exceeded the known detection threshold of the analyzer $(1 \mu \mathrm{g} \mathrm{C})$. Chytridiomycota isolates averaged 93.65 (22.55) pg C per cell. Dikarya isolates averaged 203.75 (79.54) pg C per propagule. Average values of ergosterol were used to create conversion factors to total carbon (Table 1). Ergosterol values were correlated with carbon $\left(R^{2}=0.52\right.$, SFigure 2$)$. The average ratio of carbon: ergosterol was $105.25 \mu \mathrm{g} C$ per nmol ergosterol.

LCMS analysis of environmental samples revealed the presence of all targeted sterols at every site (Fig. 2, STable 3). 24-Ethyl cholesterol was the most concentrated sterol detected, followed by cholesterol, 24-methyl cholesterol, and finally ergosterol. Ergosterol was detected in every sample. The average ergosterol value from all environmental sites (i.e. seawater and sea ice samples) was 16.54 (33.33) nmol m${ }^{-3}$; in sea ice 34.15 (38.72) $\mathrm{nmol} \mathrm{m}^{-3}$; and in seawater $9.69(29.36) \mathrm{nmol} \mathrm{m}^{-3}$. The greatest ergosterol value was measured in the algal aggregate $(379 \mathrm{nmol})$. The lowest ergosterol value was measured from Troms $\varnothing$ air $\left(0.002 \mathrm{nmol} \mathrm{m}^{-3}\right)$. Using the average carbon:ergosterol conversion factors of all cultured fungi analyzed $(105.25 \mu \mathrm{g}$ $\mathrm{C}$ per nmol ergosterol), there was an average Dikarya biomass (i.e. seawater and sea ice samples) of $1.74(3.50) \mathrm{mg}$ $\mathrm{C} \mathrm{m}^{-3}$; 3.59 (4.07) $\mathrm{mg} \mathrm{C} \mathrm{m}^{-3}$ in sea ice; and $1.02(3.09) \mathrm{mg}$ $\mathrm{C} \mathrm{m}^{-3}$ in seawater (two-tailed $T$-test, $p=0.10$ ). Integrated Dikarya biomass from all seawater sites averaged 444.56 (444.36) $\mathrm{mg} \mathrm{C} \mathrm{m}^{-2}$. Sediment trap data revealed a Dikarya biomass sedimentation rate of 2.51 and $5.34 \mathrm{mg} \mathrm{C} \mathrm{m}^{-2}$ day $^{-1}$ at 5 and $20 \mathrm{~m}$ depth, respectively. 
Table 1 Biovolume and biomass conversion factors of six aquatic fungi displaying the diameter of conidia (Dikarya) and zoosporangia (Chytridiomycota) that were used to calculate biovolume from quantified carbon values.

\begin{tabular}{|c|c|c|c|c|}
\hline & Diameter & Biomass:volume & Carbon:ergosterol & Carbon:ergosterol (w/w) \\
\hline Penicillium brevicompactum & $4-5 \mu \mathrm{m}$ & 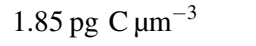 & $0.232 \mu \mathrm{g} C$ per pmol ergosterol & $1.70 \mathrm{mg}$ ergosterol $\mathrm{g} \mathrm{C}^{-1}$ \\
\hline Sarocladium strictum & $8-11 \mu \mathrm{m}$ & $0.51 \mathrm{pg} \mathrm{C} \mu \mathrm{m}^{-3}$ & $0.095 \mu \mathrm{g} \mathrm{C}$ per pmol ergosterol & $4.16 \mathrm{mg}$ ergosterol $\mathrm{g} \mathrm{C}^{-1}$ \\
\hline Hypocrea atroviridis_007 & $2-5 \mu \mathrm{m}$ & 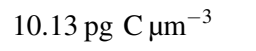 & $0.033 \mu \mathrm{g} C$ per pmol ergosterol & $11.92 \mathrm{mg}$ ergosterol $\mathrm{g} \mathrm{C}^{-1}$ \\
\hline Calycina marina TRa3180 & $5-8 \mu \mathrm{m}$ & 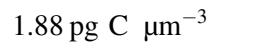 & $0.061 \mu \mathrm{g} \mathrm{C}$ per pmol ergosterol & $6.53 \mathrm{mg}$ ergosterol $\mathrm{g} \mathrm{C}^{-1}$ \\
\hline Globomyces pollinis-pini & $12-24 \mu \mathrm{m}$ & $0.0333 \mathrm{pg} \mathrm{C} \mu \mathrm{m}^{-3}$ & - & - \\
\hline Chytriomyces hyalinus & $24-125 \mu \mathrm{m}$ & $0.00039 \mathrm{pg} \mathrm{C} \mu \mathrm{m}^{-3}$ & - & - \\
\hline
\end{tabular}

Fig. 2 Heat map displaying concentrations of measured sterols at stations during the PS106 expedition and one air sample collected in Troms $\varnothing$, Norway. Darker colors represent higher concentrations. The cubed root of sample values is displayed for illustrative purposes

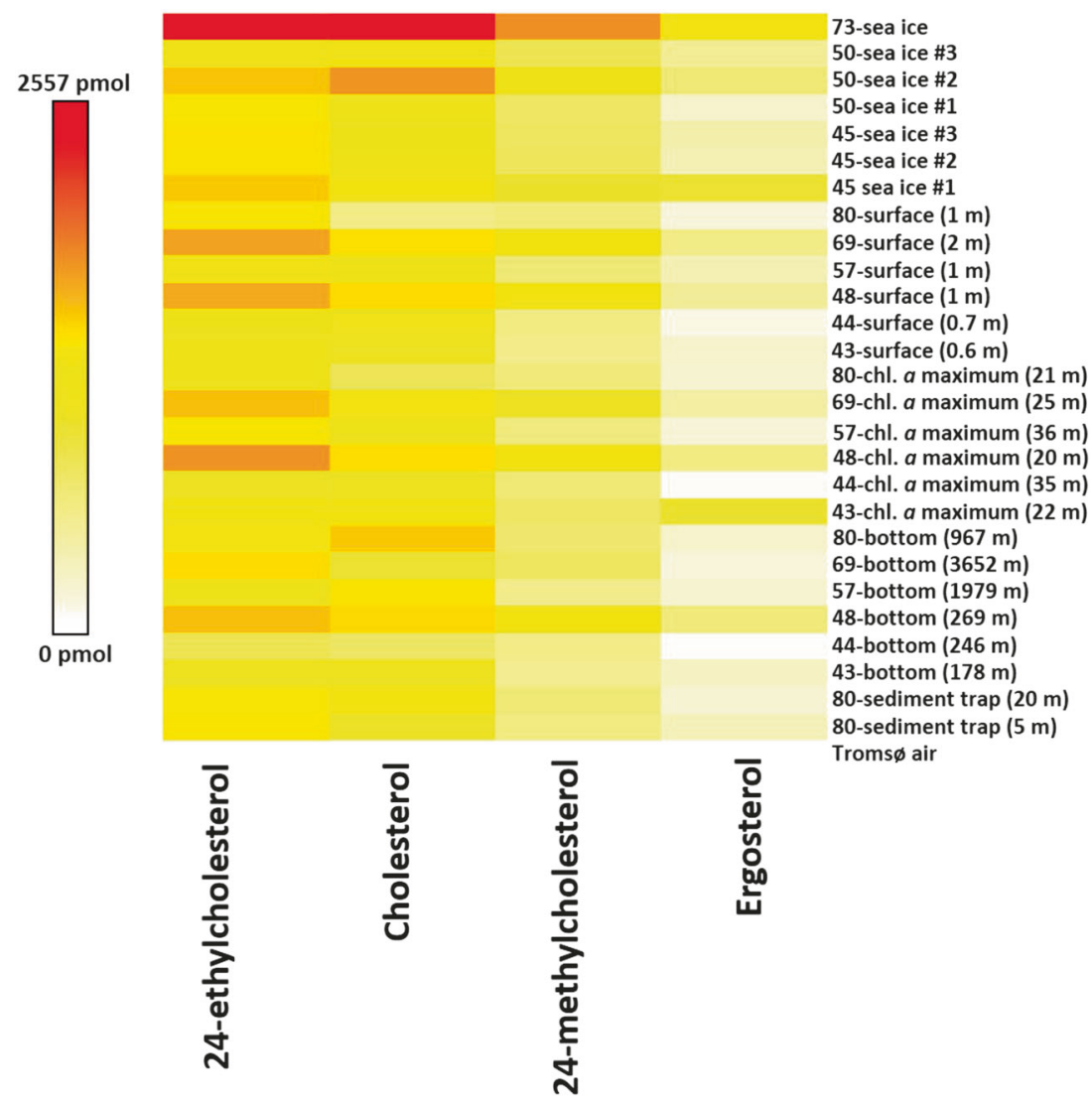

SILVA TestProbe identified that probe ChyBTH (using zero base pair mismatches) theoretically hybridized with $67 \%$ of all archived Chytridiomycota sequences, as well as unintended binding with three ciliate genera (Cardiostomatella, Hippocomos, Wilbertia), a small fraction of the Dikarya, and the Glomeromycota. SILVA TestProbe identified that probe ChyBTH2 did not theoretically hybridize with any databasearchived sequences, underscoring the potential specificity of our probe to Chytridiomycota clone sequences. SILVA TestProbe using two and three mismatches identified ciliates, metazoans, and the dinoflagellate genus Prorocentrum as the only non-specific taxa to which our probes would theoretically hybridize. We did not test the binding of our probes to the nearest non-specific taxa, as we believe the morphological differences between the Chytridiomycota and other non-specific probe hybridizing groups could be efficiently discerned. BLAST queries of our probes identified wheat (Triticum aestivum), yak (Bos mutus $>$ ), pole worm (Haemonchus contortus), and bighorn sheep (Ovis canadensis) as the only non-fungal eukaryotes with $100 \%$ identity and query coverage, as well as a bacterium (Xylella fastidiosa). CARDFISH analysis of environmental samples detected Chytridiomycota, as well as a small $(<1 \mu \mathrm{m})$ cluster-forming organism that was frequently associated with algae. Labeled cells larger than the $20 \mu \mathrm{m}$ exclusion threshold were not observed. Chytridiomycota were observed at almost every station and in almost every sample; however, there were no Chytridiomycota detected in several bottom water samples. The majority $(60 \%)$ of observed Chytridiomycota (sea ice and seawater) came from sea ice samples. Chytridiomycota 
Fig. 3 Fluorescence microscopy of CARD-FISH labeled

Chytridiomycota cells. Scale bar represents $10 \mu \mathrm{m}$. Note:

Hybridized Chytridiomycota cells fluoresced red in this study, but appear blue in the top four micrographs, based on imaging limitations. (a) A

Chytridiomycota (ch) cell attached to an unidentified algal (a) cell. (b) Numerous

Chytridiomycota zoosporangia attached to a particle. (c) Chytridiomycota zoosporangia with various diatom cells in background. (d) Two

Chytridiomycota zoosporangia and one small zoospore (z) in top left of image. (e) Laser scanning micrograph illustrating the red fluorescing

Chytridiomycota in association with signal-saturating blue DAPI-stained diatoms. (f) Laser scanning micrographs of Chytridiomycota zoosporangia in association with diatoms

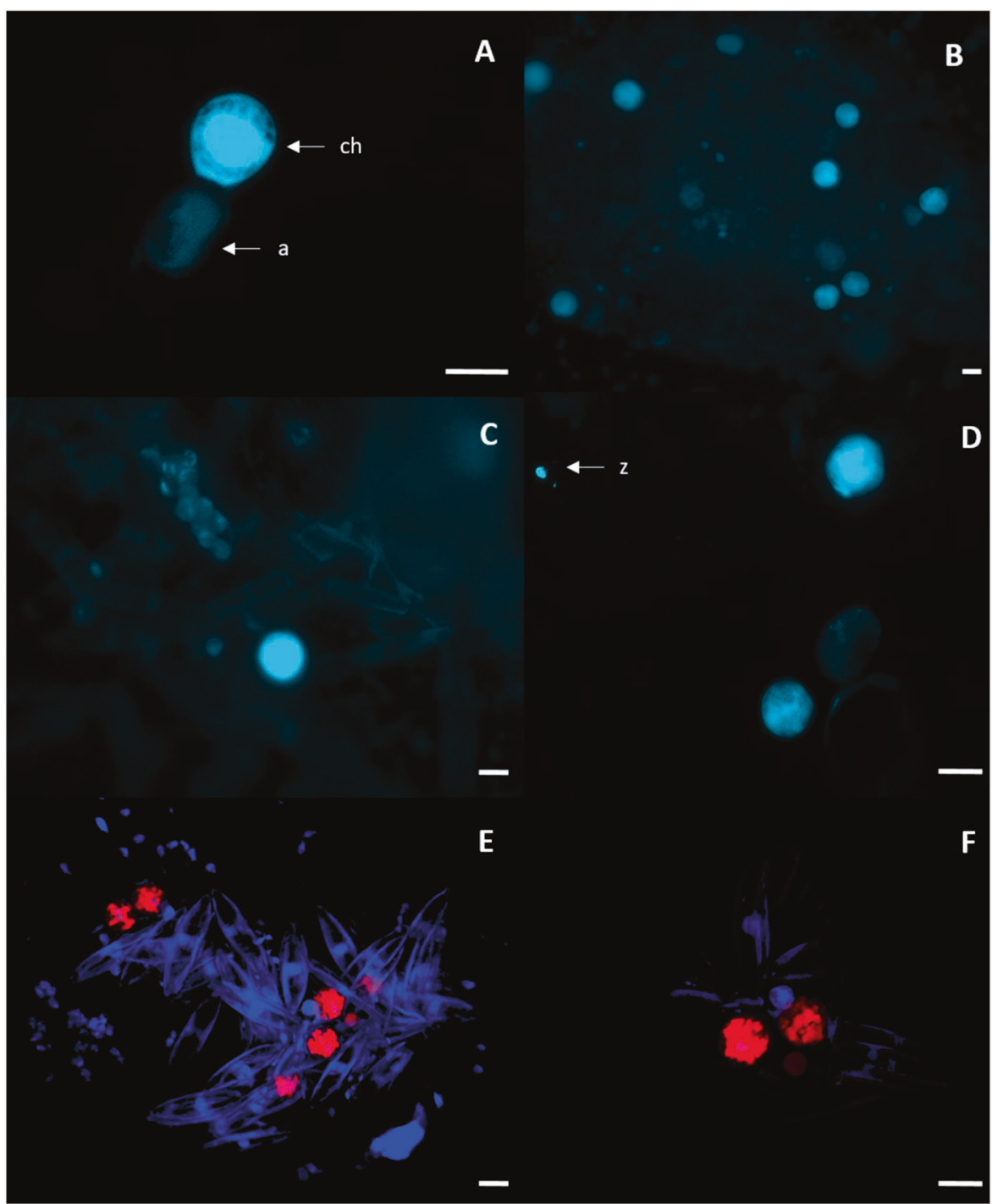

were observed attached to particles and diatoms (Fig. 3) as well as free-living cells that were not associated with any substrate. When counts were converted to carbon, Chytridiomycota biomass averaged 34.07 (50.77) $\mu \mathrm{g} \mathrm{C \textrm {Cm } ^ { - 3 }}$ across all sea ice and seawater samples; 81.57 (68.68) $\mu \mathrm{g}$ $\mathrm{C} \mathrm{m}^{-3}$ in sea ice, which was significantly higher than Chytridiomycota biomass in seawater, 15.60 (26.16) $\mu \mathrm{g} \mathrm{C} \mathrm{m}^{-3}$ (two-tailed $T$-test, $p=0.04$ ). The Chytridiomycota derived a vertically integrated seawater biomass of 11.66 (17.96) $\mathrm{mg}$ $\mathrm{C} \mathrm{m}^{-2}$. Sediment trap data revealed a Chytridiomycota sedimentation rate of $7.09 \mu \mathrm{g} \mathrm{C} \mathrm{m}^{-2}$ day $^{-1}$ at both 5 and $20 \mathrm{~m}$ depth. The average of summed ergosterol and CARDFISH biomass (sea ice and seawater) approximates 1.77 (3.52) $\mathrm{mg} \mathrm{C} \mathrm{m}^{-3} ; 3.67$ (4.10) $\mathrm{mg} \mathrm{C} \mathrm{m}^{-3}$ in sea ice; and 1.03 (3.08) $\mathrm{mg} \mathrm{C} \mathrm{m}^{-3}$ in seawater (two-tailed $T$-test, $p=0.09$ ). Summed carbon from ergosterol and CARD-FISH values derived an average vertically integrated seawater biomass of 456.23 (447.38) $\mathrm{mg} \mathrm{C} \mathrm{m}^{-2}$.
After primary PCR, in parallel with our environmental samples, visualization of DNA in agarose gel revealed no visible DNA amplification within our negative sequencing control. Using two MiSeq runs to generate sequencing data, we produced 26,677,829 assembled reads. After removal of chimeric sequences, sequences that contained ambiguous bases, unalignable sequences, and sequences allied to the Bacteria, Archaea, and Metazoa, we retained $12,767,164$ sequences. The fungal community comprised $8 \%$ of all retained reads and were allied to the Ascomycota, Basidiomycota, Mucoromycota, Chytridiomycota, and unclassifiable sequences. Fungal sequences unclassifiable to the taxonomic phylum level represented $89 \%$ of total sequences (Fig. 4). Using the remaining sequences classified, there was a noticeable mismatch between our amplicon sequencing data and ergosterol/CARD-FISH counts (linear regression of ergosterol:Dikarya sequence reads, $R^{2}=$ 0.0092; no Chytridiomycota detected in sites where CARD- 


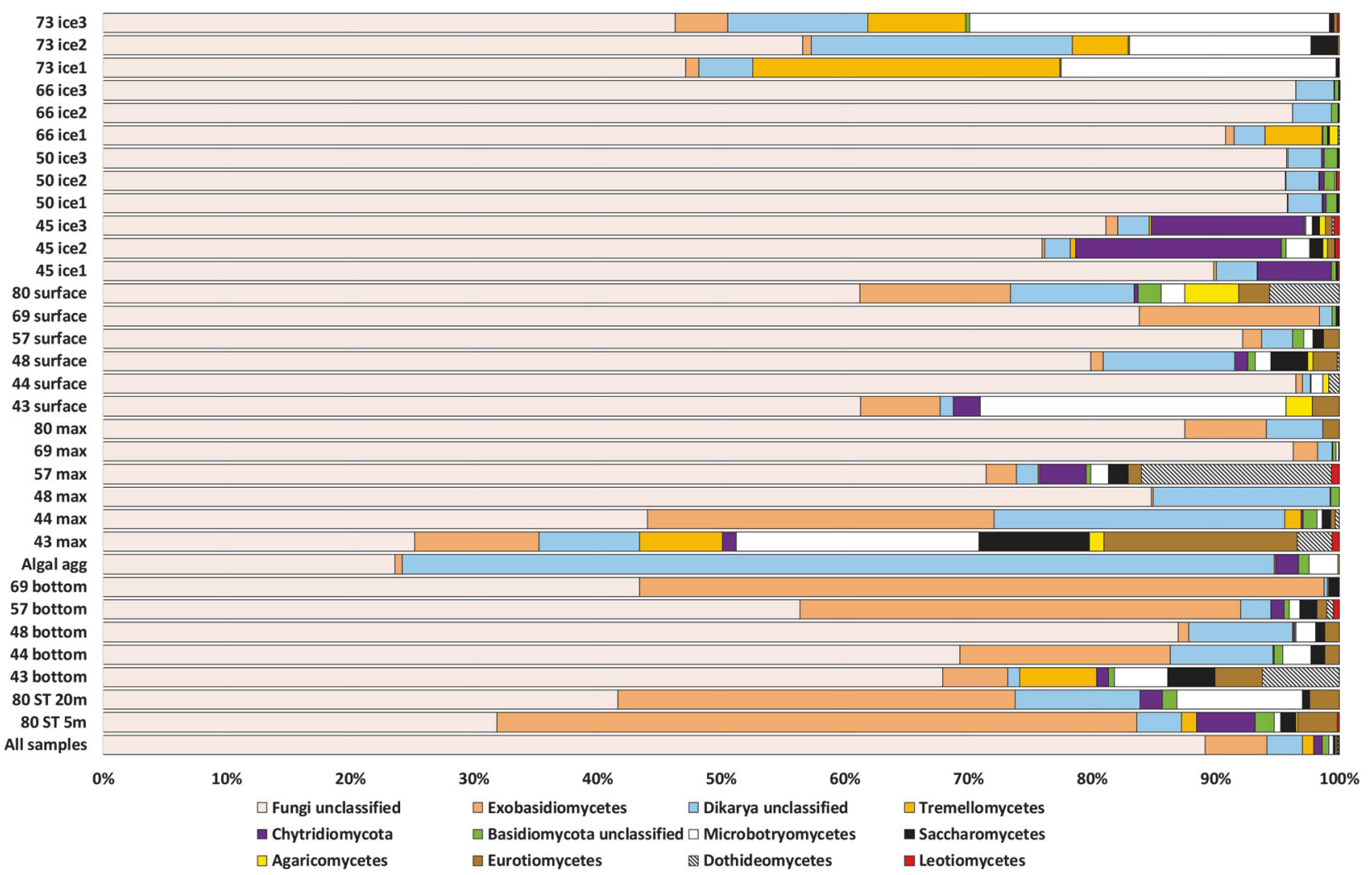

Fig. 4 Relative abundance of fungal taxa classified from 18S rRNA V9 high-throughput sequence reads generated at various stations, including surface waters, chlorophyll $a$ maximum (max), bottom samples, sediment traps (ST), sea ice, and an algal aggregate (algal agg). Taxa

FISH probes hybridized to Chytridiomycota). The three ciliate genera that our CARD-FISH probes theoretically hybridized with were not detected in our high-throughput sequencing results.

GeoChip5.0 contains 167,403 unique probes to which environmental DNA can hybridize. Environmental DNA from Barrow, Alaska sediment hybridized to 63,403 (37\%) available probes. In May sediment, environmental DNA hybridized to 56,729 probes and 55,723 probes in June sediment. Detected genes are known to be involved in biogeochemical cycling of carbon, nitrogen, sulfur, phosphate, as well as secondary metabolism. Genes from each taxonomic domain of life were detected, including 628 genes allied to the viruses (22\% of possible viral probes), including 20 genes allied to the Partitiviridae (16 RNAdependent-RNA polymerases and 4 capsid proteinencoding genes), 3450 genes allied to eukaryotes (30\% of possible eukaryotic probes), 57,388 genes allied to Bacteria (41\% of possible bacterial probes), 1633 genes allied to the Archaea (29\% of possible Archaea probes), and 304 genes derived from uncultured organisms. Hybridized fungal genes (Table 2) were represented by 2757 probes $(31 \%$ of possible fungal probes) that were derived from the Chytridiomycota, Neocallimastigomycota, Basidiomycota, and are displayed at the taxonomic class level. Chytridiomycota sequences were unclassifiable to the class level and are consequently displayed as a phylum. Taxa that contributed less than 100 sequences are not displayed for clarity

Ascomycota. Sixty-three nitrogen-cycling fungal genes were detected that help catalyze ammonification from nitrite (narG, nirK) and urea (ureC) and subsequent ammonia assimilation through glutamate synthase activity (glnA), as well as genes associated with denitrification (narG, nirK, norB). We detected genes involved in the degradation and conversion of phenolic compounds (e.g. lignins and naphthalene), such as phenylalanine $N$-monooxygenase, salicylate 1-monooxygenase, and peroxidase. Out of all functional genes detected, the fungal pel (pectin lyase) was the 26th strongest gene signal detected in May sediment, relative to all hybridized probes. In June sediment, this gene became the seventh strongest gene signal detected.

To explore the ability of a candidate marine fungus to degrade biological material, we inoculated the fecal pellets of $O$. glacialis (amphipod) with conidia of $P$. brevicompactum. Penicillium species are regularly isolated and detected in the marine realm [4]. A member of this genus was selected for this study given the global distribution of Penicillium and its presumed frequent encounters with biological material. After a month of incubation, branching hyphae were observed entwined and extending away from the fecal pellets, resulting in a loss of structural integrity to the fecal pellet (SFigure 3). P. brevicompactum is also 
Table 2 The top 25 most signal-intense fungal probes (proxy for abundance) detected in under-ice sediment from Barrow, Alaska using the GeoChip microarray

\begin{tabular}{|c|c|c|c|c|}
\hline Gene category & Probe origin & May signal & June signal & GeoChip gene name \\
\hline Carbon cycling (pectin) & Verticillium albo-atrum VaMs.102 & 23,938 & 40,240 & pel_Cdeg \\
\hline Carbon cycling (hemicellulose) & Thielavia terrestris NRRL 8126 & 11,394 & 22,482 & ara \\
\hline Antiphagocytosis & Trametes versicolor & 11,120 & 5802 & lip \\
\hline Antibiotic resistance (transporter) & Penicillium marneffei ATCC 18224 & 6164 & 3007 & ABC_antibiotic_transporter \\
\hline antioxidant enzyme & Podospora anserina $\mathrm{S}$ mat + & 5508 & 4164 & per_fun \\
\hline Carbon cycling (phospholipids) & Uncinocarpus reesii 1704 & 5016 & 7963 & phospholipase_D_fungi \\
\hline Carbon cycling (cellulose) & Phanerochaete chrysosporium & 4630 & 3313 & exoglucanase \\
\hline Antioxidant enzyme & Marasmius scorodonius & 4197 & 3199 & per_fun \\
\hline Carbon cycling (chitin) & Uncinocarpus reesii 1704 & 3768 & 7074 & chitinase \\
\hline Antioxidant enzyme & Clavispora lusitaniae ATCC 42720 & 3710 & 8760 & per_fun \\
\hline Carbon cycling (lignin) & Ganoderma lucidum & 3332 & 3842 & phenol_oxidase \\
\hline Carbon cycling (phospholipids) & Ajellomyces capsulatus $\mathrm{H} 143$ & 3124 & 7631 & phospholipase_D_fungi \\
\hline Carbon cycling (pectin) & Chaetomium globosum CBS 148.51 & 3102 & 1839 & pme_Cdeg \\
\hline Metal homeostasis (chromium transporter) & Aspergillus nidulans FGSC A4 & 2926 & 1855 & ChrA \\
\hline Carbon cycling (protein) & Magnaporthe oryzae 70-15 & 2913 & 2201 & metalloprotease_fungi \\
\hline Carbon cycling (phospholipids) & Ajellomyces capsulatus NAm1 & 2846 & 7558 & phospholipase_A2_fungi \\
\hline Carbon cycling (tannins) & Aspergillus nidulans FGSC A4 & 2838 & 7177 & tannase_Cdeg \\
\hline Carbon cycling (lignin) & Phanerochaete sordida & 2535 & 2399 & mnp \\
\hline Carbon cycling (pectin) & Magnaporthe grisea $70-15$ & 2484 & 1145 & pme_Cdeg \\
\hline Metal homeostasis (chromium transporter) & Pyrenophora tritici-repentis $\mathrm{Pt}-1 \mathrm{C}-\mathrm{BFP}$ & 2385 & 1135 & ChrA \\
\hline Metal homeostasis (iron transporter) & Magnaporthe grisea $70-15$ & 2350 & 3716 & iron_permease_high_affinity \\
\hline Drought tolerance & Schizophyllum commune H4-8 & 2322 & 1554 & tre_fun \\
\hline Antibiotic resistance (transporter) & Nectria haematococca mpVI 77-13-4 & 2110 & 956 & ABC_multidrug_fungi \\
\hline Carbon cycling (cutin) & Verticillium albo-atrum VaMs.102 & 2107 & 1739 & cutinase \\
\hline Nitrogen assimilation & Ajellomyces capsulatus NAm1 & 2024 & 706 & nitrate_reductase \\
\hline
\end{tabular}

regularly isolated from the terrestrial realm, consistent with approximately $40 \%$ of described marine fungal taxa [4]. Consequently, we were interested to explore the longevity of terrestrial-marine fungal taxa. After 8 months of incubation in sterile seawater, we were able to germinate $P$. brevicompactum spores on PmTG agar media (SFigure 4). Spores germinated overnight and produced long germination tubes that extended away from the conidium.

\section{Discussion}

A surge of recent molecular-based studies have demonstrated that marine fungi are abundantly present in a variety of marine ecosystems [6, 7, 38]; however, the ecological relevance of marine fungi remains a knowledge gap in food web ecology and biological oceanography. In this study, we targeted a geographically distinct region of the Arctic that includes the Atlantic-influenced Norwegian Sea, the Barents Sea, and along the shelf-break region that descends into the deep Arctic Ocean (>3000 m depth). Our objective was to explore the ecological contributions of marine fungi, by focusing on the fungal fraction (Dikarya and Chytridiomycota) that comprises $>95 \%$ of the entire fungal community in Arctic marine ecosystems [8, 18, 20]. We quantified fungal-derived sterols, used Chytridiomycotaspecific enzyme-labeled probes, established biomass conversion factors, screened for catalytic genes, and conducted lab-based studies to explore putative ecological roles of Arctic marine fungi.

We used high-throughput sequencing to explore the relationship between ergosterol and sequence reads and to serve as a check for the presence of non-Dikarya ergosterolsynthesizing organisms, as well as unintended organisms to which our CARD-FISH probes would hybridize. We detected four major fungal phyla: Ascomycota, Basidiomycota, Chytridiomycota, the Mucoromycota, as well as unclassifiable sequences, consistent with other sequencingbased studies from across the Arctic $[8,18,20]$. However, we identified a strong mismatch between rRNA barcode sequences and our ergosterol and CARD-FISH quantifications. These data underscore the limited utility of ampliconbased data for quantitative measurements. Still, our rRNA results identified a small fraction of the fungal community 
that was unreachable with our CARD-FISH and ergosterol methods, such as the Mucoromycota. Consequently, from this perspective, our data likely underestimate the total ecological contributions of marine fungi in the sampled area.

To establish a baseline of fungal biomass, we generated carbon:ergosterol ratios for four Dikarya isolates and established cell-specific carbon values for two Chytridiomycota isolates. Our average weight ergosterol $\mathrm{g} \mathrm{C}^{-1}$ ( $6.08 \mathrm{mg}$ ergosterol $\mathrm{g} \mathrm{C}^{-1}$ ) is consistent with other estimates between 2.3 and $11.5 \mathrm{mg}$ ergosterol $\mathrm{g}^{-1}$ biomass [39]. Our Chytridiomycota biomass estimate $(0.4 \mathrm{pg} \mathrm{C}$ per zoospore) is substantially lower than other (10.7 pg C per zoospore) published studies [40], assuming a zoospore diameter of 3$4 \mu \mathrm{m}$ for $G$. pollinis-pini [41] and 5-6 $\mu \mathrm{m}$ for $C$. hyalinus [42]. This low value was driven by the wide range of sporangial diameters that were observed in culture. To circumvent this issue, we chose to use the average carbon value (93.6 pg C per cell) of all sorted particles (i.e. zoospores and zoosporangia), which we believe is more representative of actual environmental conditions, where Chytridiomycota are encountered in different stages of their lifecycle. The absence of cultured marine Chytridiomycota inhibited our use of marine isolates to generate conversion factors. Though Arctic marine Chytridiomycota form distinct phylogenetic clades, they branch among other described taxonomic orders [18, 43], and with a mature zoosporangium diameter of $\sim 10 \mu \mathrm{m}$, are within the size range reported of freshwater algal parasites [44]. Consequently, we believe parallels can be drawn between freshwater and marine Chytridiomycota. Still, these biomass estimates are sensitive to the assessed carbon values generated from select fungal cultures that were applied to the environment. As a result, the average carbon value of isolates and consequently integrated biomass estimates are likely to change as the number of analyzed cultures increase.

The ergosterol synthesis pathway shares common sterol precursors with most eukaryotes, originating with squalene that is converted to lanosterol. Subsequently, lanosterol can be converted to cholesterol in vertebrates and ergosterol in fungi [45]. Ergosterol biosynthesis has also arisen independently in other eukaryotic lineages, such as in the human pathogens Trypanosoma and Acanthamoeba [46] and is speculated to be present in the marine genera Chlamydomonas [47], Corallochytrium, and Capsaspora [48, 49]. We conducted high-throughput sequencing as a check for these organisms and found minimal evidence for ergosterol contributions from non-fungal sources. Specifically, 20 sequences were classified as Acanthamoeba in our dataset (maximum five sequences in an ice core at station 50). We acknowledge the possibility that other uncharacterized marine organisms might produce ergosterol. In addition to ergosterol, we quantified three additional sterols known to dominate the sterol pool in fungi; however, these sterols are also synthesized by other organisms and are therefore of minimal use for exclusively quantifying fungal biomass. The concentration of these other sterols is likely elevated due to the presence of small metazoans and other cholesterol-synthesizing taxa, but are still reflective of the total quantity in our environmental samples.

To supplement our ergosterol-based fungal biomass estimates of the Dikarya, we conducted CARD-FISH counts to enumerate the Chytridiomycota. The high number of chytrids in sea ice relative to seawater is consistent with other sequencing-based studies from the Arctic [8]. Furthermore, the presence of the Chytridiomycota in the water column has been confirmed in other global marine ecosystems with CARD-FISH methods [50] and in the Arctic with sequencing data [6]. Chytridiomycota biomass estimates from other ecosystems approximate that $\sim 15 \%$ of the carbon biomass can be tied up seasonally by the Chytridiomycota [40]. Our combined estimate of total fungal biomass (i.e. summed ergosterol and CARD-FISH based biomass) of $1.77 \mathrm{mg} \mathrm{C} \mathrm{m} \mathrm{m}^{-3}$ from sea ice and seawater is between $<1$ and $15 \%$ of the total carbon historically observed in this study's sampling region [51]. Comparative analysis of ergosterol and CARD-FISH counts suggest that ergosterolsynthesizing organisms comprise the majority of marine fungal biomass. However, the absence of the Chytridiomycota at several bottom depth sites skewed extrapolated values of biomass, especially in deep-water sites; consequently, we believe we underestimate the biomass of the Chytridiomycota.

The carbon values of detected fungi appeared randomly distributed throughout the water column, consistent with other sequencing-based studies across the Arctic [18]. Complex hydrography [11] and sea ice within our study region confound the elucidation of ecological drivers of fungal abundances. Furthermore, terrestrial contributions of Dikarya fungi into the marine ecosystem likely skews the interpretation of marine fungal biomass and sequencing data. We determined that some spores of the terrestrial and marine-inhabiting fungus, $P$. brevicompactum, can remain viable for at least 8 months in seawater, underscoring the possible detection of viable, terrestrial-derived fungal propagules in the marine environment. Future research should attempt to discern terrestrial and marine-derived fungal carbon to marine ecosystems, while detailing the relative proportions of latent and active marine fungal propagules.

The average fungal-derived carbon values in seawater of $1.04 \mathrm{mg} \mathrm{C} \mathrm{m}{ }^{-3}$ is similar to other estimates of pelagic marine fungal biomass from Chile [52]. The average fungalderived carbon value of seawater of $444.56 \mathrm{mg} \mathrm{C} \mathrm{m}^{-2}$ in mid-summer is similar to biomass of other major morphologically defined groups in the Arctic. For example, algal 
pigments in sea ice and seawater combined is between 10 and $300 \mathrm{mg} \mathrm{m}^{-2}[53,54]$; mesozooplankton biomass in the Arctic Ocean ranges between 1 and $2 \mathrm{~g} \mathrm{C} \mathrm{m}^{-2}$ [53, 55]; bacterial biomass in the upper $50 \mathrm{~m}$ has varied between 0.2 and $0.5 \mathrm{~g} \mathrm{C} \mathrm{m}^{-2}$ [56, 57]. Our fungal biomass estimates are surprisingly high relative to bacterial biomass; however, fungal and prokaryotic biomass are analogous in this study to biomass reported in other oceanic regions [52]. Though these late-summer estimates are comparable to other taxa, Arctic marine fungal abundances (namely the Chytridiomycota) are known to temporally modulate in association with algae and increased irradiance $[8,58]$. Our high values of fungi (both Dikarya and Chytridiomycota) on the algal aggregate support these findings. In other sectors of the world, members of the Dikarya also display predictable patterns of temporal modulation in association with the varying ecological niches they occupy $[52,59]$. We detected ergosterol at every station and observed fungi attached to non-living particulate. Based on these observations, we hypothesize that non-algal associated fungi might comprise larger fractions of total biomass under aphotic conditions [9]. Unlike phototrophic organisms, fungal production can be sustained by dissolved organic material in the absence of light, such as in deep sea sediment [60] or during the polar night. Observations suggest that fungal production is at least partially constrained by consumers and routed into other trophic levels. Screening of molecular barcodes has detected fungi in the gut content of zooplankton [19]; however, no additional data exist for the fate of fungal-derived carbon. We present evidence for the presence of marine mycoviruses within the Partitiviridae [61] identified in our GeoChip analysis, suggesting an additional pathway of carbon flow in the Arctic Ocean-presumably back into the dissolved organic carbon pool.

To supplement biomass estimates and conceptually explore fungal ecology outside of an exclusively trophic paradigm, a functional gene survey was conducted on surface sediment samples from Barrow, Alaska. We detected numerous genes allied to fungi that are responsible for degradative processes and nutrient cycling. For example, we detected fungal genes that assimilate nitrate/nitrite, and degrade refractory substances, such as naphthalene and lignin. The fungal pectin lyase gene was the seventh strongest probe signal detected in June sediment (the period after ice-sourced biological material settles to the seafloor), suggesting that fungi might actively be degrading biological material, while uptaking dissolved organic material and nutrients [62]. The successful germination of fungal spores in zooplankton fecal pellets augments these findings. This is particularly important in the Arctic, where rapidly sinking zooplankton fecal pellets provide essential carbon to benthic organisms [63]. When these data are considered with our quantified fungal biomass sedimentation rates and microscopy observations of Chytridiomycota on particulate, these data suggest that benthic-pelagic carbon coupling is likely influenced by the successful colonization of sinking particulate by fungi in the upper water column, consistent with observation from the bathypelagic realm [9]. The presence and activity of nutrient-cycling gene products are likely responsible for the relationship of fungal communities to dissolved nutrients that have been identified in other sectors of the world [64, 65]. However, the relationship between complex organic molecules and fungal communities in the marine realm remains unknown. As thawing permafrost continues to be exported into the Arctic Ocean, the presence of known catalytic genes suggest an ecological niche for Arctic marine fungi. Future research should explore the potential synergy and niche portioning between the bacteria and the fungi, especially as their biomass is similar and they both encode degradative genes.

The unique genetic signatures of marine fungi as well as the inconspicuous morphology of fungal propagules have challenged the easy identification and subsequent integration of fungal data into marine ecology. Mounting data suggest that marine fungi are cosmopolitan organisms that can comprise a sizable fraction of the eukaryotic microbial community. Here we provide several lines of data that demonstrate the relevance and ecological potential of marine fungi in their associated ecosystems. Ultimately, these data suggest that fungi could be as important in oceanic ecosystems as they are in freshwater environments.

Acknowledgements We would like to acknowledge the funding support provided by UiT - the Arctic university of Norway and the Troms $\emptyset$ Research Foundation under the project Arctic SIZE, number $01 \mathrm{VM} / \mathrm{H} 15$. We greatly acknowledge the support by the science team and the crew of the RV Polarstern and the grant support from AWI_PS106_00. We would like to thank Paul Dubourg and Roy Andres Lysa from the University of Troms $\varnothing$ for assistance with the CHN analyzer and with the flow cytometer, respectively, as well as Randi Olsen and Augusta Hlin Aspar Sundbø for assistance with laser scanning microscopy. We would like to acknowledge Céline Heuzé for generating CTD profiles and Thomas Isakeit from Texas A\&M University for his spore trap. Analytical chemistry was supported by a United States Department of Agriculture's Agriculture and Food Research Initiative grant (2017-67013-26524). Sequencing data has been submitted to the NCBI SRA under BioBroject ID PRJNA449189, accession SAMN08888854-SAMN08888884. Microarray data have been archived in NCBI GEO, under accession GSE117831, GSM3309953-GSM3309954.

\section{Compliance with ethical standards}

Conflict of interest The authors declare that they have no conflict of interest.

Publisher's note: Springer Nature remains neutral with regard to jurisdictional claims in published maps and institutional affiliations. 


\section{References}

1. Berbee ML, James TY, Strullu-Derrien C. Early diverging fungi: diversity and impact at the dawn of terrestrial life. Annu Rev Microbiol. 2017;71:41-60.

2. Blackwell M. The fungi: 1, 2, 3...5.1 million species? Am J Bot. 2011;98:426-38.

3. Hawksworth DL, Lucking R. Fungal diversity revisited: 2.2 to 3.8 million species. Microbiol Spectr. 2017. https://doi.org/10.1128/ microbiolspec.FUNK-0052-2016.

4. Jones EBG, Suetrong S, Sakayaroj J, Bahkali AH, Abdel-Wahab MA, et al. Classification of marine Ascomycota, Basidiomycota, Blastocladiomycota and Chytridiomycota. Fungal Divers. 2015;73:1-72.

5. Freeman KR, Martin AP, Karki D, Lynch RC, Mitter MS, Meyer $\mathrm{AF}$, et al. Evidence that chytrids dominate fungal communities in high-elevation soils. Proc Natl Acad Sci USA. 2009;106: 18315-20.

6. Comeau AM, Vincent WF, Bernier L, Lovejoy C. Novel chytrid lineages dominate fungal sequences in diverse marine and freshwater habitats. Sci Rep. 2016;6:30120.

7. Rojas-Jimenez K, Wurzbacher C, Bourne EC, Chiuchiolo A, Priscu JC, Grossard HPl. Early diverging lineages within Cryptomyocta and Chytridiomyocta dominate the fungal communities in ice-covered lakes of the McMurdo Dry Valleys, Antarctica. Sci Rep. 2017;7:1.

8. Hassett BT, Gradinger R. Chytrids dominate Arctic marine fungal communities. Environ Microbiol. 2016;18:2001-9.

9. Bochdansky AB, Clouse MA, Herdl GJ. Eukaryotic microbes, principally fungi and Labyrinthulomycetes, dominate biomass on bathypelagic marine snow. ISME J. 2017;11:362-73.

10. Rämä T, Hassett BT, Bubnova E. Arctic marine fungi: from filaments and flagella to operational taxonomic units and beyond. Bot Mar. 2017;60:433-52.

11. Bluhm BA, Kosobokova KN, Carmack EC. A tale of two basins: an integrated physical and biological perspective of the deep Arctic Ocean. Prog Oceanogr. 2015;139:89-121.

12. Hansell DA, Kadko D, Bates NR. Degradation of terrigenous dissolved organic carbon in the Western Arctic Ocean. Sci. 2004;304:858-61.

13. Neff JC, Finlay JC, Zimov SA, Davydov SP, Carrasco JJ, Schuur EAG, et al. Seasonal changes in the age and structure of dissolved organic carbon in Siberian rivers and stream. Geophys Res Lett. 2006;33:L23401.

14. Dashtban M, Schraft H, Syed TA, Qin W. Fungal biodegradation and enzymatic modification of lignin. Int $\mathrm{J}$ Biochem Mol Bio. 2010;1:36-50.

15. Wotton RS, Malmqvist B. Feces in aquatic ecosystems: feeding animals transform organic matter into fecal pellets, which sink or are transported horizontally by currents; these fluxes relocate organic matter in aquatic ecosystems. Bioscience. 2001;51:537-44.

16. Turner JT. Zooplankton fecal pellets, marine snow, phytodetritus and the ocean's biological pump. Prog Oceaogr. 2015;130:205-48.

17. Richardson MJ. Diversity and occurrence of coprophilous fungi. Mycol Res. 2001;105:387-402.

18. Hassett BT, Ducluzeau AL, Collins RE, Gradinger R. Spatial distribution of aquatic marine fungi across the western Arctic and sub-Arctic. Environ Microbiol. 2017;19:475-84.

19. Cleary AC, Soreide JE, Freese D, Neihoff B, Gabrielsen TM. Feeding by Calanus glacialis in a high arctic fjord: potential seasonal importance of alternative prey. ICES J Mar Sci. 2017;74:1937-46.

20. Zhang T, Wang NF, Zhang YQ, Liu HY, Yu LY. Diversity and distribution of fungal communities in the marine sediments of Kongfjorden, Svalbard (High Arctic). Sci Rep. 2015;5:14524.
21. Rämä $T$, Davey ML, Nordén J, Halvorsen R, Blaalid R, Mathiassen GH, et al. Fungi sailing the Arctic Ocean: speciose communities in North Atlantic driftwood as revealed by highthroughput amplicon sequencing. Microb Ecol. 2016;72: 295-304.

22. Dupont S, Lemetais G, Ferreira T, Cayot P, Gervais P, Beney L. Ergosterol biosynthesis: a fungal pathway for life on land? Evolution. 2012;66:2961-8.

23. Weete JD, Abril M, Blackwell M. Phylogenetic distribution of fungal sterols. PLoS ONE. 2010;5:e10899.

24. Mille-Lindblom C, von Wachenfeldt E, Tranvik LJ. Ergosterol as a measure of living fungal biomass: persistence in environmental samples after fungal death. J Microbiol Methods. 2004;59:25362.

25. Medina A, Probanza A, Gutierrez Manero FJ, Azcon R. Interactions of arbuscular-mycorrhizal fungi and Bacillus strains and their effects on plant grwoth, microbial rhizosphere activity (thymidine and leucine incorporation) and fungal biomass (ergosterol and chitin). Appl Soil Ecol. 2003;22:15-28.

26. Lee C, Howarth RW, Howes BL. Sterols in decomposing Spartina alterniflora and the use of ergosterol in estimating the contribution of fungi to detrital nitrogen. Limnol Oceanogr. 1980;25:290-303.

27. Newell SY. Fungal biomass and productivity. Method Microbiol. 2001;30:357-72.

28. Vernet M, Richardson TL, Metfies K, Nöthig EM, Peeken I. Models of plankton community changes during a warm water anomaly in Arctic waters show altered trophic pathways with minimal changes in carbon export. Front Mar Sci. 2017. https:// doi.org/10.3389/fmars.2017.00160.

29. Stoeck T, Bass D, Nebel M, Christen R, Jones MDM, Breiner HW, et al. Multiple marker parallel tag environmental DNA sequencing reveals a highly complex eukaryotic community in marine anoxic water. Mol Ecol. 2010;19:21-31.

30. Schloss PD, Westcott SL, Ryabin T, Hall JR, Hartmann M, Hollister EB, et al. Introducing mothur: open-source, platformindependent, community-supported software for describing and comparing microbial communities. Appl Environ Microbiol. 2009;75:7537-41.

31. Kozich JJ, Westcott SL, Baxter NT, Highlander SK, Schloss PD. Development of a dual-index sequencing strategy and curation pipeline for analyzing amplicon sequence data on the MiSeq Illumina sequencing platform. Appl Environ Microbiol. 2013;79:5112-20.

32. Quast C, Pruesse E, Yilmaz P, Gerken J, Schweer T, Yarza P, et al. The SILVA ribosomal RNA gene database project: improved data processing and web-based tools. Nucleic Acids Res. 2013;41:D590-D596.

33. Edgar RC, Haas BJ, Clemente JC, Quince C, Knight R. UCHIME improves sensitivity and speed of chimera detection. Bioinformatics. 2011;27:2194-2200.

34. Ludwig W, Strunk O, Westram R, Richter L, Meier H, Yadhu kumar, et al. ARB: a software environment for sequence data. Nucleic Acids Res. 2004;32:1363-71.

35. Pernthaler A, Pernthaler J, Amann R. Fluorescence in situ hybridization and catalyzed reporter deposition for the identification of marine bacteria. Appl Envrion Microbiol. 2002;6:3094101.

36. He Z, Gentry TJ, Schadt CW, Wu L, Liebich J, Chong SC, et al. GeoChip: a comprehensive microarray for investigating biogeochemical, ecological and environmental processes. ISME J. 2007;1:67-77.

37. Van Nostrand JD, Yin H, He Z, Zhou J. Hybridization of environmental microbial community nucleic acids by GeoChip. Methods Mol Biol. 2016;1399:183-96.

38. Picard KT. Coastal marine habitats harbor novel early-diverging fungal diversity. Fungal Ecol. 2017;25:1-13. 
39. Gessner MO, Chauvet E. Ergosterol-to-biomass conversion factors for aquatic hyphomycetes. Appl Environ Microbiol. 1993;59:502-7.

40. Maier MA, Peterson TD. Enumeration of parasitic chytrid zoospores in the Columbia River via quantitative PCR. Appl Environ Microbiol. 2016;82:3857-67.

41. Letcher PM, Vélez CG, Barrantes MA, Powell MJ, Churchill PF, Wakefield WS. Ultrastructural and molecular analyses of Rhizophydiales (Chytridiomycota) isolates from North America and Argentina. Mycol Res. 2008;112:759-82.

42. Karling JS. Brazilian chytrids. VI. Rhopalophlyctis and Chytriomyces, two new chitionphilic operculate genera. Am J Bot. 1945;32:362-9.

43. Lepelletier F, Karpov SA, Alacid E, Le Panse S, Bigeard E, Garcés E, et al. Dinomyces arenysensis gen. et sp. nov. (Rhizophydiales, Dinomycetaceae fam. nov.), a chytrid infecting marine dinoflagellates. Protist. 2014;165:230-44.

44. Van den Wyngaert S, Rojas-Jimenez K, Seto K, Kagami M, Grossart H-P. Diversity and hidden host specificity of chytrids infecting colonial volvocacean algae. J Eukaryot Microbiol. 2018;65:870-81.

45. Desmond E, Gribaldo S. Phylogenomics of sterol synthesis: insights into the origin, evolution, and diversity of a key eukarotic feature. Genome Biol Evol. 2009;1:364-81.

46. Martin-Navarro CM, Lorenzo-Morales J, Machin RP, LópezArencibia A, Garcia-Castelleno JM, de Fuentes I, et al. Inhibition of 3-hydroxy-3-methylglutaryl-coenzyme A reductase and application of statins as a novel effective therapeutic approach against Acanthamoeba infections. Antimicrob Agents Chemother. 2013;57:375-81.

47. Brumfield KM, Laborde SM, Moroney JV. A model for the ergosterol biosynthetic pathway in Chlamydomonas reinhardtii. Eur J Phycol. 2017;52:64-74.

48. Najile SR, Molina MC, Ruiz-Trillo I, Uttaro AD. Sterol metabolism in the filasterean Capsaspora owczarzaki has features that resemble both fungi and animals. Open Biol. 2016;6:160029.

49. Sumathi JC, Raghukumar S, Kasbekar DP, Raghukumar C. Molecular evidence of fungal signatures in the marine protist Corallochytrium lamacisporum and its implications in the evolutions of animals and fungi. Protist. 2006;157:363-76.

50. Lepère C, Ostrowski M, Hartmann M, Zubkow MV, Scanlan DJ. In situ associations between marine photosynthetic picoeukaryotes and potential parasites - a role for fungi? Environ Microbiol Rep. 2016;8:445-51.

51. Reigstad M, Wexels Riser C, Wassmann P, Ratkova T. Vertical export of particulate organic carbon: attenuation, composition and loss rates in the northern Barents Sea. Deep-Sea Res Pt II. 2008;55:2308-19.

52. Gutiérrez MH, Pantoja S, Tejos E, Quiñones RA. The role of fungi in processing marine organic matter in the upwelling ecosystem off Chile. Mar Biol. 2011;158:205-19.

53. Wheeler PA, Gosselin M, Sherr E, Thibaultc D, Kirchman DL, Benner R, et al. Active cycling of organic carbon in the central Arctic Ocean. Nature. 1996;380:697-9.

54. Gradinger R. Sea ice algae: major contributors to primary production and algal biomass in the Chukchi and Beaufort Seas during May/June 2002. Deep-Sea Res Pt II. 2009;56:1201-12.

55. Auel H, Hagen W. Mesozooplankton community structure, abundance and biomass in the central Arctic Ocean. Mar Biol. 2002;140:1013-21.

56. Sherr EB, Sherr BF, Fessenden L. Heterotrophic protists in the central Arctic Ocean. Deep-Sea Res Pt II. 1997;44:1665-82.

57. Sherr EB, Sherr BF, Wheeler PA, Thompson K. Temporal and spatial variation in stocks of autotrophic and heterotrophic microbes in the upper water column of the central Arctic Ocean. Deep-Sea Res Pt I. 2003. https://doi.org/10.1016/S0967-0637(03) 00031-1.

58. Terrado R, Medrinal E, Dasilva C, Thaler M, Vincent WF, Lovejoy C. Protist community composition during spring in an Arctic flaw lead polynya. Polar Biol. 2011;34:1901-14.

59. Taylor JD, Cunliffe M. Multi-year assessment of coastal planktonic fungi reveals environmental drivers of diversity and abundance. ISME J. 2016;10:2118-28.

60. Orsi W, Biddle FJ, Edgcomb V. Deep sequencing of subseafloor eukaryotic rRNA reveals active fungi across marine subsurface provinces. PLOS ONE 2013;8:e56335.

61. Ghabrial SA, Castrón JR, Jiang D, Nibert ML, Suzuki N. 50-plus years of fungal viruses. Virology. 2015;479:356-68.

62. Ortega-Arbulú A-S, Pichler M, Vuillemin A, Orsi WD. Effects of organic matter and low oxygen on the mycobenthos in a coastal lagoon. Environ Microbiol. 2018. https://doi.org/10.1111/14622920.14469

63. Grebmeier JM, Barry JP. The influence of oceanographic processes on pelagic-benthic coupling in polar regions: a benthic perspective. J Mar Sci. 1991;2:495-518.

64. Jeffries TC, Curlevski NJ, Brown MV, Harrison DP, Doblin MA, Petrou K, et al. Partitioning of fungal assemblages across different marine habitats. Environ Microbiol Rep. 2016;8:235-8.

65. Sun JY, Song Y, Ma ZP, Zhang HJ, Yang ZD, Cai ZH, et al. Fungal community dynamics during a marine dioflagellate (Noctiluca scintillans) bloom. Mar Environ Res. 2017;131: 183-94. 